\title{
Changes in barrier function of a model intestinal epithelium by intraepithelial lymphocytes require new protein synthesis by epithelial cells
}

\author{
C T Taylor, A Murphy, D Kelleher, A W Baird
}

\begin{abstract}
Background-Elements of the mucosal immune system may play an important part in regulating epithelial barrier function in the intestinal tract. Intraepithelial lymphocytes (IELs) represent a subtype of immunocyte which is strategically placed to regulate epithelial function at most mucosal sites.
\end{abstract}

Aims and methods-An IEL derived cell line (SC1) was used to examine its effects on the model epithelium T84 - a tumour derived cell line which retains the phenotype of colonic crypt cells. Transepithelial electrical resistance (TER) was used as a marker of epithelial integrity.

Results-Coculture of T84 cells with SC1 produced a significant fall in TER as did exposure of T84 monolayers to IEL derived supernatant. Recombinant interferon- $\gamma$ (rIFN $\gamma$ ) also reduced TER in T84 monolayers. Cycloheximide prevented the effects of IEL supernatant and of rIFN $\gamma$ on TER. The fall in TER in response to rIFN $\gamma$ was attenuated by blocking antibodies, which did not alter the fall in resistance induced by IEL supernatant. Fractions of IEL supernatant, separated on the basis of size, evoked temporally distinct changes in TER. Ultrastructural studies support the hypothesis that the slow onset but severe fall in TER indicates catastrophic effects on the monolayer. The more rapid onset fall in TER was not associated with gross changes in monolayer morphology. Reduction of TER by IEL supernatant was not influenced by inhibitors of tyrosine phosphatase or of protein kinase $C$. Although herbimycin did reduce the rapid onset change in TER, the tyrosine kinase inhibitor genistein did not alter responses to IEL supernatant.

Conclusions-Mucosal $T$ cells may influence barrier function by $a$ process involving new protein synthesis by epithelial cells. This model may have relevance in some inflammatory conditions of the gastrointestinal tract. (Gut 1997; 40: 634-640)

Keywords: inflammation, intraepithelial lymphocytes, epithelia, coeliac disease, cytokines, immunopharmacology.

Epithelial cells represent a dynamic boundary, which, although regarded as a structural component of the innate immune system, plays a part in regulation of acquired immunity at sensory and effector levels. ${ }^{1}$ The barrier is incomplete because macromolecules may pass between or across epithelial cells. Thus the epithelial layer has the capacity to regulate antigen access to elements of the immune system. This study examines how selected cells of the immune system, in particular the intraepithelial lymphocyte population (IEL), may regulate barrier function of a model epithelium. The intraepithelial lymphocyte population represents a specialised $T$ cell population intercalated between epithelial cells in the human gastrointestinal tract. These cells have a distinctive phenotype, being predominantly $\mathrm{CD} 3+, \mathrm{CD} 8+$, and $\mathrm{HML}-1+.^{23}$ Whereas most human IELs are TCR $\alpha \beta+$, the proportion of $\gamma \delta+$ IELs is increased in some gastrointestinal disorders. ${ }^{4}$ The function of the IEL population remains unclear. It has been suggested that it represents a primitive line of defence against intestinal pathogens. ${ }^{5}$ The finding that these cells utilise a restricted $T$ cell gene repertoire provides support for such a primitive function. ${ }^{6}$

Previous studies suggest that IELs are effector cells capable of secreting cytokines in response to stimulation through the $T$ cell receptor or through $\mathrm{CD} 2 .{ }^{7}$ Cytokines secreted by IELs include tumour necrosis factor- $\alpha$ (TNF $\alpha$ ), interferon- $\gamma(\mathrm{IFN} \gamma)$, and the interleukins (IL) IL-2, IL-4, and IL-5 and it is suggested that IFN $\gamma$ and $\mathrm{TNF} \alpha$ can act directly on intestinal epithelia to mediate changes in epithelial permeability and capacity for electrogenic ion transport. ${ }^{89}$ Recent data from coculture experiments have shown that IEL-like cells induce changes in structural and functional integrity in epithelial cell monolayers which may be mediated by cytokine generation by lymphocytes. ${ }^{10}$

The aim of this study was to examine the influence of lymphocytes, including both IELs and peripheral blood lymphocytes (PBLs), on barrier function of a representative colonic epithelial cell line, T84. We used transepithelial electrical resistance (TER) to monitor changes in barrier function over time during exposure of individual monolayers to lymphocytes, lymphocyte derived supernatant, or selected recombinant cytokines. Pharmacological methods were used in an effort to characterise the mechanism underlying induced changes in TER. 


\section{Methods}

\section{CELL CULTURES}

T84 cells

T84 (originally derived from a colonic crypt cell carcinoma ${ }^{11}$ ) epithelial cells obtained from the American Type Culture Collection (Rockville, MD, USA) were grown and passaged in a 1:1 mixture of Ham's F-12 and Dulbecco's MEM medium which was supplemented with L-glutamine $(2 \mathrm{mM})$, penicillin $(100 \mathrm{U} / \mathrm{ml})$, streptomycin (100 $\mu \mathrm{g} / \mathrm{ml})$, mercaptoethanol $(50 \mu \mathrm{M})$, HEPES $(1 \mathrm{mg} / \mathrm{ml})$, and $10 \%$ fetal calf serum. T84 cells were split using trypsin (with EDTA) and seeded $\left(1 \times 10^{6}\right.$ cells/filter $)$ on semipermeable support membrane cell culture inserts (area $1.13 \mathrm{~cm}^{2}$; Falcon Labware). T84 cells were used between passage numbers 65 and 70 .

IELS

IELs were isolated and maintained as described previously. ${ }^{12}$ SC-1 is an IEL cell line established by stimulation of the IELs (obtained after epithelial isolation from coeliac duodenal biopsy specimens) with the mitogens PMA and PHA. SC-1 cells express CD44, LFA-1, VLA-1, HML-1, and $\alpha 6$ integrin. The cell line contains a mixture of $\alpha \beta(65 \%)$ and $\gamma \delta(29 \%)$ TCR phenotypes. IELs were activated for one week (PMA; $1 \mathrm{ng} / \mathrm{ml}$ and PHA; $10 \mu \mathrm{g} / \mathrm{ml}$ ) in Rothwell Park Memorial Institute (RPMI) medium, washed four times in fresh media (RPMI medium), and resuspended at a density of $1 \times 10^{6}$ cells/ml before culture with epithelial cells.

Peripheral blood lymphocytes were prepared from blood collected aseptically from normal, healthy volunteers using centrifugation on a density gradient (Lymphoprep ${ }^{\circledR}$ ) and activated with PHA ( $25 \mathrm{ng} / \mathrm{ml}$ for 72 hours), followed by three washes.

PREPARATION AND TREATMENT OF IEL SUPERNATANT

Lymphocytes were prepared as described above and cultured for 48 hours. The cells were then removed by centrifugation (1500 rpm for 10 minutes) after which the supernatant was collected, stored in aliquots, and frozen at $-70^{\circ} \mathrm{C}$ until required. In experiments in which neutralising antibodies were used, supernatants were preincubated for 20 minutes with antibody before culture with epithelial cells. When pharmacological agents were present, they were added into the IEL supernatant before culture with epithelial monolayers. Separation of supernatant into $>30 \mathrm{kDa}$ and $<30 \mathrm{kDa}$ fractions was achieved with a Centricon-30 filtration system. Cytokine assays of IEL and PBL supernatants were carried out by enzyme linked immunosorbent assay (ELISA) for IFN $\gamma^{13}$ and by L929 bioassay for $T N F \alpha^{14}$ as previously described.

ELECTROPHYSIOLOGICAL STUDIES Growth of the epithelial monolayers on the semipermeable supports was monitored by measuring TER using the Endohm ${ }^{\circledR}$ apparatus (World Precision Instruments, New Haven CT, USA), at 24 hour intervals. When confluent, cells formed high resistance monolayers which were stable over 96 hours. Typically monolayers reached stable high resistance at 10-14 days after initial seeding.

Confluent monolayers of T84 cells grown on cell culture inserts were exposed to $1 \times 10^{6}$ cells $/ \mathrm{ml}$ IELs or $1 \mathrm{ml}$ undiluted supernatant in the sub-basolateral domain at time zero. Control monolayers were treated with fresh RPMI medium. After treatment, TER across the monolayers was monitored over a range of time points $(4,24,48$, and 72 hours) in a sterile environment using the Endohm $^{\circledR}$ apparatus.

\section{ELECTRON MICROSCOPY}

Monolayers were fixed in $2.5 \%$ glutaraldehyde in phosphate buffered saline (PBS), $\mathrm{pH} 7 \cdot 4$, for 30 minutes at $37^{\circ} \mathrm{C}$. Monolayers were postfixed in $1 \%(\mathrm{w} / \mathrm{v})$ osmium tetroxide in PBS for 60 minutes, dehydrated through ascending grades of alcohol, and treated with propylene oxide for 30 minutes before embedding in epon resin at $60^{\circ} \mathrm{C}$ overnight. Ultrathin sections were cut with a diamond knife and stained with uranyl acetate and lead citrate. Representative regions from each of the groups under investigation were examined with a JEOL 200FX transmission electron microscope.

\section{CYTOTOXICITY ASSAY}

Lactate dehydrogenase (LDH) release from T84 monolayers was determined colorimetrically using a commercially available assay system (CytoTox96 ${ }^{\circledR}$; Promega, Madison, WI, USA). To compensate for enzyme instability in medium over the time course of these experiments, cellular rather than media $\mathrm{LDH}$ concentrations were measured. Results, expressed as units of optical density, were used to calculate $\mathrm{LDH}$ concentrations in control and supernatant treated samples. Measurements were carried out in triplicate. As positive controls, experiments were performed in which complement was used (data not shown).

\section{ANALYSIS}

Results are expressed as means (SEM). For statistical comparisons, analysis of variance or Student's $t$ tests were performed as appropriate on raw data. For clarity, information is expressed in graphic, time course format as a percentage of control values at the beginning of each experiment.

\section{Results}

BASAL CHARACTERISTICS OF T84 MONOLAYERS The TER of T84 monolayers increased in a time dependent manner over 10-15 days after initial seeding of cells onto filters. After this growth period, the TER stabilised (1115 (117) $\Omega . \mathrm{cm}^{2}$ ) and remained stable over 72 


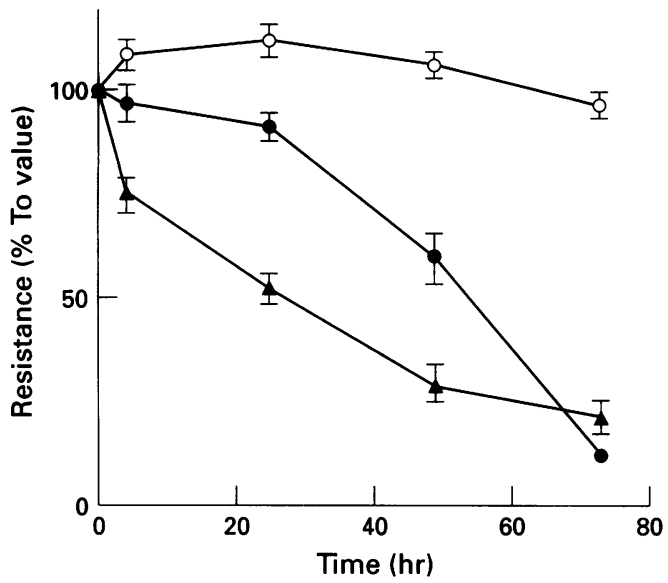

Figure 1: Transepithelial resistance (TER) values in untreated confluent T84 monolayers was stable over 72 hours (open circles; $n=49)$. Exposure of confluent monolayers to IEL cells $\left(10^{6}\right.$ SC1 cells maintained in the basolateral bathing solution) caused a slow onset, almost complete abolition of TER (closed circles; $n=6$ ). IEL supernatant applied to the basolateral domain of confluent monolayers caused a rapid onset, almost complete reduction in TER (triangles; $n=24)$. Results are expressed as means (SEM).

Values are given as $a \%$ of respective time zero values.

hours (Fig 1, n=49). The transepithelial potential difference was $1.4(0.3) \mathrm{mV}$; lumen negative $(n=49)$. The same (retrospective) controls were pooled and used for all experiments.

COCULTURE WITH IEL CAUSES

PERMEABILISATION OF T84 MONOLAYERS

IELs were cocultured in the basolateral bathing medium $\left(1 \times 10^{6}\right.$ cells in $\left.1 \mathrm{ml}\right)$ of filter grown confluent T84 monolayers. Forty eight hours after addition of the lymphocytes, TER had significantly dropped to 59 (6)\% of the pretreatment value $(\mathrm{p}<0.001, \mathrm{n}=6)$. This permeabilising effect continued over time with TER falling to $12(2) \%$ of the pretreatment value after 72 hours (Fig 1). Exposure to supernatant from IELs also significantly reduced TER. Supernatant, however, caused a more rapid reduction in TER, which reached significance $(75(4) \%$ of the pretreatment value, $n=24, p<0.001$ ) four hours after onset of treatment (Fig 1). RPMI medium alone was without effect on TER in control monolayers.

Temporally distinct changes in TER

\begin{tabular}{lll}
\hline & \multicolumn{2}{l}{$\%$ of time zero TER } \\
\cline { 2 - 3 } Treatment (n) & $4 h r$ & $72 \mathrm{hr}$ \\
\hline Control (49) & $109(4) \mathrm{NS}$ & $96(3) \mathrm{NS}$ \\
PBL (17) & $104(3) \mathrm{NS}$ & $11(2)^{\star \star \star}$ \\
IEL (6) & $97(5) \mathrm{NS}$ & $12(2)^{\star \star \star}$ \\
IELsn (24) & $75(4)^{\star \star \star}$ & $21(4)^{\star \star \star}$ \\
IELsn+cycloheximide (9) & $89(6) \mathrm{NS}$ & $102(6) \mathrm{NS}$ \\
IELsn<30 kDa (6) & $70(5)^{\star \star}$ & $85(6) \mathrm{NS}$ \\
IELsn>30 kDa (9) & $92(7) \mathrm{NS}$ & $18(2)^{\star \star \star}$ \\
IELsn+herbimycin (9) & $95(6) \mathrm{NS}$ & $14(1)^{\star \star \star}$ \\
IELsn+genistein (5) & $64(6)^{\star \star \star}$ & $25(2)^{\star \star \star}$ \\
IELsn+staurosporine (5) & $85(14) \mathrm{NS}$ & $21(1)^{\star \star \star}$ \\
IELsn+Ro-31-8220 (5) & $48(4)^{\star \star \star}$ & $20(1)^{\star \star \star}$
\end{tabular}

Results are expressed as means (SEM) in normalised (\%) form for clarity; sn=supernatant; statistical analysis was by one way analysis of variance (ANOVA) (followed by Tukey-Kramer post-test) to compare resistance measurements $\left(\Omega \cdot \mathrm{cm}^{2}\right)$ with respective time zero values. Thus effects are compared with internal, matched controls. None of the drugs, when added alone, altered TER

${ }^{\star} \mathrm{p}<0.05 ;{ }^{\star \star} \mathrm{p}<0.01 ;{ }^{\star \star \star} \mathrm{p}<0.001$
Exposure of T84 monolayers to IEL supernatant had no effect on transepithelial potential difference. Control and treated values respectively were $-0.9(0.5) \mathrm{mV}$ and $-0.1(0.6)$ $\mathrm{mV}$ at four hours and were $-2.6(0.4) \mathrm{mV}$ and $-4.8(0 \cdot 3) \mathrm{mV}$ at 48 hours ( $\mathrm{n}=6$ throughout). These low potential difference values indicate that the preparations are electrically silent during the course of the experiments.

We used a four hour pulse challenge after which the IEL supernatant was replaced with normal medium. The fall in TER (29 (2)\%, $\mathrm{p}<0.01, \mathrm{n}=4)$ over four hours was reversible and had recovered to 96 (5)\% of control values by 48 hours after the first challenge.

Coculture of T84 monolayers with PBLs $\left(10^{6}\right.$ cells/well) also caused a fall in TER which was not evident after four hours of incubation but was significant 72 hours after the experiment began (Table).

MOLECULAR SIEVING OF IEL SUPERNATANT PRODUCES TWO FRACTIONS WITH DISTINCT ACTIVITIES

Supernatant was separated into fractions of greater and less than $30 \mathrm{kDa}$. Basolateral culture of T84 monolayers with each fraction evoked temporally distinct effects on TER. Incubation with the $<30 \mathrm{kDa}$ fraction resulted in an initial reduction in TER to 70 (5)\% of the pretreatment value within four hours $(n=6$; $\mathrm{p}<0.01$; Table); however, no further reduction occured after this. By contrast, the fraction of supernatant containing only molecules $>30$ $\mathrm{kDa}$ produced a slower onset reduction in TER to $18(2) \%$ of the pretreatment value after 72 hours ( $p<0.001 ; n=9$; Table) with no rapid change in TER, which was 92 (7)\% of control values four hours after the start of the experiment.

IFN $\gamma$ BUT NOT TNF $\alpha$ REDUCES T84 TER

Addition of IFN $\gamma(300 \mathrm{ng} / \mathrm{ml})$ to the basolateral bathing medium of the T84 monolayers resulted in a time dependent fall in TER of T84 monolayers (Fig 2A). TER was reduced to 37 (3) $\%$ of the pretreatment value ( $p<0.001$; $\mathrm{n}=11) 72$ hours after IFN $\gamma$ treatment. TNF $\alpha$ ( $6 \mathrm{ng} / \mathrm{ml} ; \mathrm{n}=6$ ) had no effects on TER even after 72 hours of incubation (Fig 2A).

Neutralising antibodies to IFN $\gamma(1 \mu \mathrm{g} / \mathrm{ml}$; $\mathrm{n}=5$ ) significantly altered the permeabilising effects of the recombinant cytokine on T84 monolayers but did not inhibit the effects of IEL supernatant on TER ( $n=16$; Fig $2 B$ ).

Concentrations of $\mathrm{TNF} \alpha$ and IFN $\gamma$ in the IEL supernatant were $0.65 \mathrm{ng} / \mathrm{ml}$ and $3.01 \mathrm{ng} / \mathrm{ml}$ respectively. Concentrations of rTNF $\alpha$ and rIFN $\gamma$ added were about 100 and 10 times greater respectively than those of endogenous cytokines measured in the supernatant.

CYCLOHEXIMIDE INHIBITS PERMEABILISATION OF T84 MONOLAYERS BY IEL SUPERNATANT AND IFN $\gamma$ In the presence of the protein synthesis inhibitor cycloheximide (1 $\mu \mathrm{g} / \mathrm{ml})$, IEL 

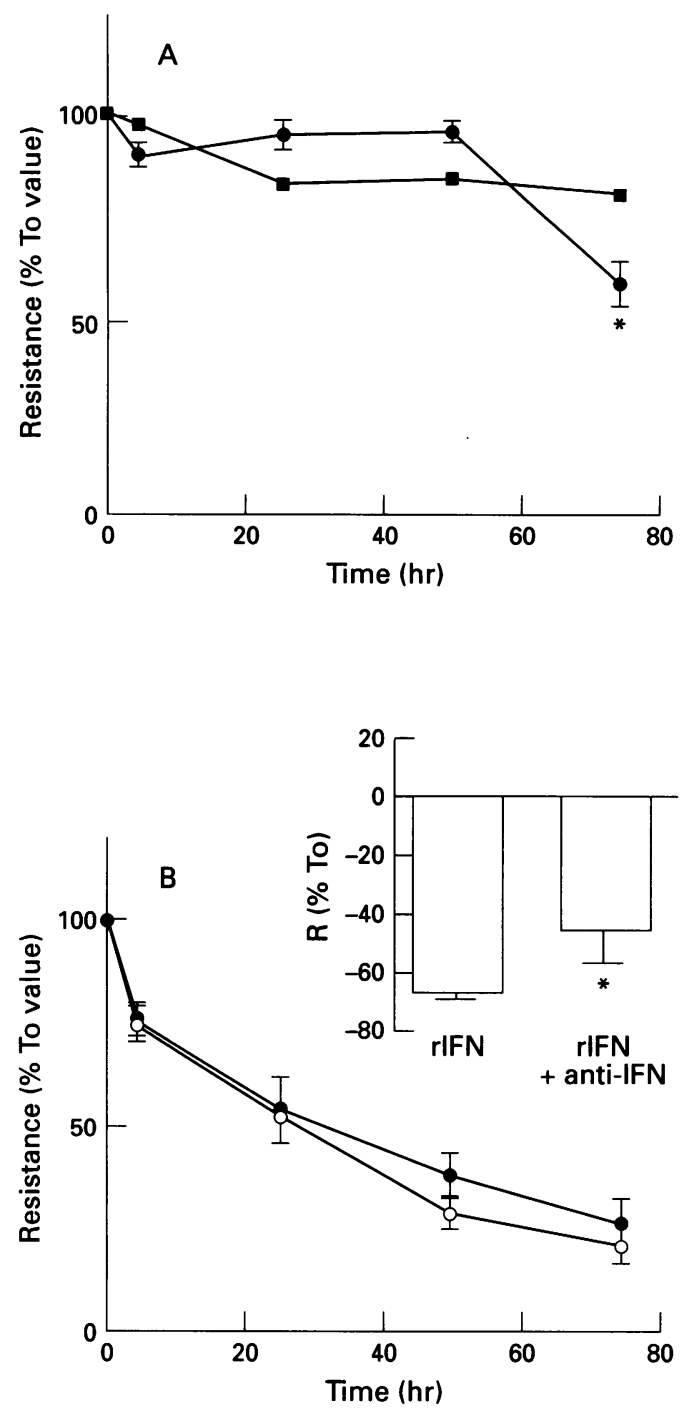

Figure 2: (A) Recombinant IFN $\gamma$ caused a significant reduction in TER by 72 hours (closed circles) whereas recombinant TNF $\alpha$ did not (closed squares). (B) IEL supernatant caused a rapid onset permeabilisation of $T 84$ epithelial monolayers over 72 hours (open circles). This effect was not inhibited in the presence of blocking antibodies against IFN $\gamma$ (closed circles). However, blocking antibodies to IFN $\gamma$ did significantly inhibit effects of recombinant IFN $\gamma$ on TER of T84 monolayers after 96 hours incubation (inset). Results are expressed as means (SEM). Values are given as a $\%$ of respective time zero values. ${ }^{\star} p<0.05$ when test and control values are compared by Student's $\mathrm{t}$ test.

supernatant caused no significant reduction in TER in the epithelial monolayers ( $p>0.05$; $\mathrm{n}=9$; Fig 3). The permeabilising effects of IFN $\gamma$ were also inhibited by the presence of cycloheximide ( $p>0.05 ; n=6 ;$ Fig 3 inset). Cycloheximide alone at the same concentration which inhibited the effects of supernatant did not alter basal TER in epithelial monolayers compared with untreated controls.

INHIBITORS OF TYROSINE KINASE, TYROSINE PHOSPHATASE OR PROTEIN KINASE C DO NOT INHIBIT IEL SUPERNATANT EFFECTS ON TER The effects of IEL supernatant on TER were examined in the presence of the tyrosine kinase inhibitors herbimycin A $(2 \mu M ; n=9)$ and genistein $(20 \mu M ; n=5)$. Herbimycin $A$, but not genistein, prevented the IEL supernatant induced fall in TER at four hours after
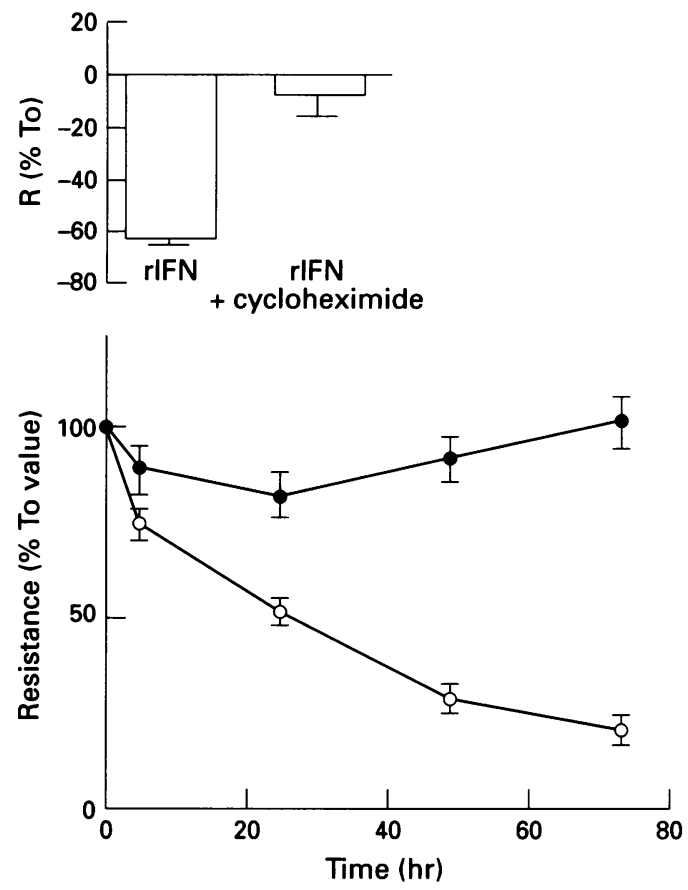

Figure 3: IEL supernatant caused a significant reduction in TER by four hours and continued over a period of 72 hours (open circles). In the presence of the protein synthesis inhibitor cycloheximide $(1 \mu \mathrm{g} / \mathrm{ml})$, the permeabilising effects of IEL supernatant were inhibited and no significant reduction in TER occurred (closed circles). Cycloheximide also significantly inhibited the permeabilising effects of recombinant IFNy (inset). Results are expressed as means (SEM). Values are given as a \% of respective time zero values.

challenge (Table). Neither of the drugs altered the effects of IEL supernatant at 72 hours.

The protein kinase $\mathrm{C}$ inhibitors staurosporine (100 $\mathrm{nM} ; \mathrm{n}=5)$ and Ro-31-8220 (10 $\mu M ; n=5)$ were also ineffective in inhibiting supernatant effects on TER. Ro-31-8220 accelerated the fall in TER, which was significantly greater at the four hour time point than in the corresponding control.

\section{IEL SUPERNATANT DOES NOT CAUSE CELL}

NECROSIS

Concentrations of $\mathrm{LDH}$ measured in cytosol of T84 cells treated with IEL supernatant (1:2 dilution in culture media) for 24 hours were not different from those in untreated control monolayers (optical density values $0.678(0.003)$ and $0.661(0.005)$ respectively; $n=6$ in each case). Benzamide ( $500 \mu \mathrm{M} ; \mathrm{n}=7)$, an inhibitor of polyADP ribosylation - which is involved in cell necrosis - did not inhibit the effect of IEL supernatant on T84 monolayer TER.

\section{ULTRASTRUCTURE OF T84 MONOLAYERS}

Electron micrographs showed monolayer preservation in control filters with maintenance of basal nuclear array and abundant microvilli (Fig 4A). By contrast, supernatant treatment of T84 cell monolayers for 48 hours resulted in overlap of cells, although junctional complexes were, at least in part, retained (Fig 4C).

Considerable nuclear disarray, loss of microvilli, and mitochondrial damage was also seen. These findings confirmed that structural 

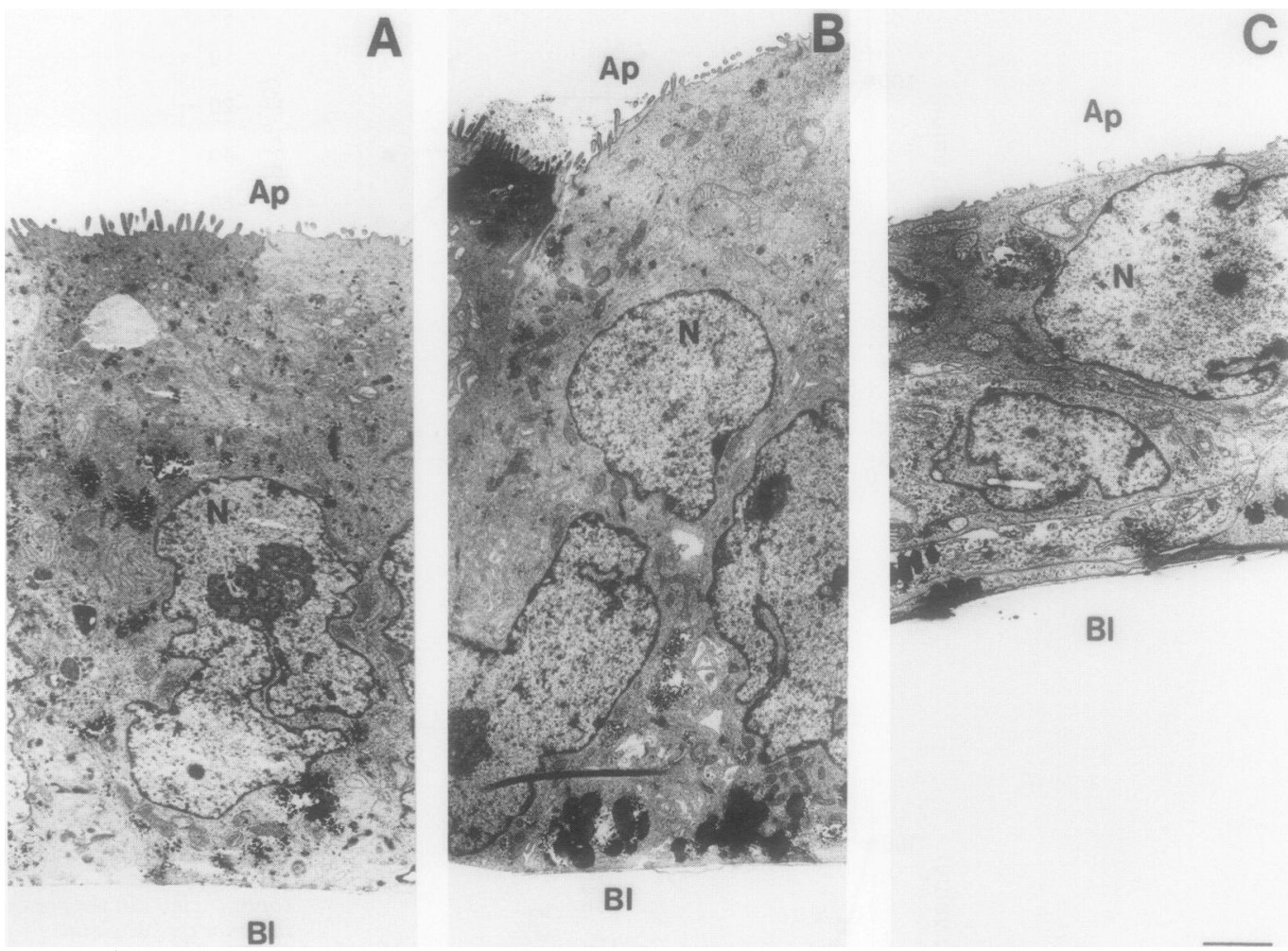

Figure 4: Transmission electromicrographs of $T 84$ monolayers. Apical (Ap) and basolateral (Bl) domains and nuclei $(N)$ are labelled. The horizontal bar represents $2 \mu \mathrm{m}$. Control tissues $(A)$ showed conserved monolayer structure which is polarised with basal array of nuclei and evident microvilli on the apical surface. Tissues exposed to IEL supernatant for four hours $(B)$ show that polarity is maintained, microvilli are visible but there are signs of nuclear disarray. After exposure of T84 monolayers to IEL supernatant for 48 hours $(C)$, there is cell overlap, monolayer flattening, and loss of microvilli.

damage occurred after incubation of T84 monolayers with IEL supernatant. The appearances at four hours were intermediate; the general architecture of the monolayer seemed to be largely conserved, abundant microvilli were still evident, but there was early evidence of nuclear disarray and mitochondrial disruption (Fig 4B).

\section{Discussion}

T-84 cells have been previously used in model systems for intestinal secretion and barrier function. ${ }^{15}$ In these experiments T84 monolayers were grown to confluency on semipermeable membrane supports on which the monolayers generated and maintained a high and steady TER. The experiments described show clearly that activated lymphocytes are capable of mediating changes in TER in T84 cells. As TER may be used as a marker of epithelial integrity, ${ }^{16}$ we conclude that the lymphocyte induced and the supernatant induced changes are caused by enhancement of permeability. An alternative explanation is that the fall in TER may be a consequence of increased transcellular conductance caused by activation of chloride secretion. However, as electrogenic ion transport in T84 cells is coupled to changes in transepithelial potential difference, ${ }^{11}$ this is an unlikely explanation because exposure to IEL supernatant did not alter potential difference.

Significant changes in permeability could be induced by the cell line SC1 derived from a human intraepithelial cell lineage when the two cell types were cocultured. The ratio of immunocyte:epithelial cells in our experiments (about 1:2) is within the normal physiological range. ${ }^{10}$ These changes were not entirely dependent on cell to cell contact as they were similar to changes in response to supernatants derived from IELs. However, there was a difference in the rate of fall in TER in epithelial cells in direct contact with SC-1 cells than in T84 cells exposed to IEL supernatant. The fall in TER in monolayers exposed to supernatant was more rapid than that in coculture experiments. It is possible that either (a) cell to cell interactions may be responsible for this difference, or $(b)$ due to higher concentrations of the secreted factor(s) at the epithelial site; different time courses may reflect the time required for secreted cytokines to accumulate to an active concentration.

The changes in TER seem to be dependent on protein synthesis by the T84 cells as they were completely prevented by cycloheximide which on its own did not alter TER. In preliminary efforts to characterise the signalling molecule we used several techniques. Firstly, we utilised recombinant cytokines IFN $\gamma$ and $\mathrm{TNF} \alpha$, which have previously been reported to be involved in intestinal inflammation ${ }^{17}$ and both of which were measurable in IEL supernatant. In our experiments, IFN $\gamma$ but not TNF $\alpha$ reduced TER in T84 cells. Thus IFN $\gamma$ may be one of the mediators involved, in keeping with findings by other investigators. ${ }^{918-21}$ These experiments do not exclude the possibility that TNF $\alpha$ could act as a cofactor or as a priming factor for other cytokines. 
However, we did not find inhibition of TER reduction by IEL supernatant in the presence of neutralising antibodies to TNF $\alpha$ or IFN $\gamma$. IFN blocking antibody was capable of inhibiting the effects of recombinant IFN although the blockade was incomplete. As many cytokines including $\mathrm{TNF} \alpha$ and IFN $\gamma$ are $<30 \mathrm{kDa}$ we used a molecular sieve to separate two fractions, which were separately tested. The results indicate that there may be two components to the IEL supernatant induced fall in TER.

Involvement of intracellular second messenger systems in T84 monolayers exposed to IEL supernatant was investigated using various pharmacological tools. Protein kinase C dependent pathways of chloride secretion in T84 cells have been extensively studied. There is much evidence that protein kinase $C$ is a negative signalling pathway which, on activation, inhibits electrogenic chloride secretion. ${ }^{1522}$ Prolonged down regulation of protein kinase $\mathrm{C}$ increased T84 permeability through structural disassembly, ${ }^{23}$ consistent with a putative role for protein kinase $\mathrm{C}$ in regulation of epithelial tight junctions. ${ }^{24}$ In our experiments, the protein kinase $\mathrm{C}$ inhibitors staurosporine $^{25}$ and Ro-31-8220 did not prevent the the fall in TER induced by IEL supernatant. Indeed, Ro-31-8220, regarded as a more selective inhibitor of protein kinase $C$, may have enhanced the initial fall in TER.

As the actions of several cytokines including interferons may be mediated by tyrosine kinase regulated gene expression ${ }^{26}$ we examined the modification of TER responses to IEL supernatant in the presence of the tyrosine kinase inhibitors herbimycin $\mathrm{A}^{27}$ and genistein. ${ }^{28}$ Herbimycin $\mathrm{A}$, but not genistein, prevented the rapid (four hour) fall in TER. This may be accounted for by a non-selective action of herbimycin, which is known to interact with thiol groups. ${ }^{27}$ Alternatively, differential selectivity of the two inhibitors has been reported and may account for the capacity of herbimycin to block the immediate onset effect whereas genistein does not. ${ }^{29}$ Herbimycin may also have direct effects via binding to transcription factors. ${ }^{33}$ The precise role of tyrosine phosphorylation could be best assessed by direct measurement (by western blotting) in cells exposed to IEL supernatant using antiphosphotyrosine antibodies.

Other studies have indicated that immune cells including IEL-like cells disrupt membrane barrier function in epithelial monolayers. For example Kaoutzani et al ${ }^{10}$ demonstrated that coculture of T84 monolayers with a mucosal derived $T$ lymphocyte cell line produced an impairment in epithelial barrier function which seemed to require direct lymphocyte apposition to epithelial basolateral membranes. Furthermore, they showed that such cell to cell contact produced soluble factors which were used to influence directly the barrier function of naive T84 monolayers. Our experiments show a similar lymphocyte evoked fall in TER in a coculture model in which cell to cell contact was not a feature. However, there are some significant differences between this and other studies both in technical approach and in conclusions reached. Our measurements permitted time course evaluation using multiple measurements on a single filter rather than selecting a single time point for evaluation. With the modified technique we have identified temporally distinct phases in the fall in TER. In experiments using coculture, the onset of the TER response was rather slow. By contrast, IEL supernatant produced a rapid onset fall in TER which was significant within four hours and this may be due to differences in concentrations of the secreted factor(s) at the epithelial cell receptor site. These data are consistent with the fall in TER being dependent on de novo synthesis of factors by the activated IEL population.

IFN $\gamma$ is a candidate messenger substance which has been reported to produce reductions in T84 barrier function. Recent studies ${ }^{9}$ concluded that IFN $\gamma$ alone could not account for the changes in coculture experiments. Our preliminary results indicate that IFN $\gamma$ did not contribute to the initial rapid reduction in TER although IFN $\gamma$ was capable of inducing a delayed fall in TER in T84 cells. We do not think that IFN $\gamma$ is the principal factor contributing to the second phase reduction in TER induced by IEL supernatants. Firstly, the time course for IFN $\gamma$ induced reduction in TER shows that the reduction in TER is not evident for at least 48 hours by which time a near maximal reduction is evident in monolayers exposed to IEL supernatant. Secondly, neutralising antibody which significantly attenuated the effects of recombinant IFN was without effect on the late phase response to IEL supernatant. Finally, concentrations of IFN $\gamma$ measured in the supernatants were much lower than those with which we showed a direct effect on TER. In agreement with a previous study ${ }^{30}$ we found no significant effect of TNF $\alpha$ on epithelial barrier function, even at concentrations of $\mathrm{TNF} \alpha$ which were much greater than those measurable in IEL supernatant.

Cell to cell signalling mechanisms remain to be identified. Our results with cycloheximide indicate that the two components of the response we describe are each dependent on protein synthesis by the epithelial cell. Cycloheximide alone did not affect the barrier function of confluent T84 monolayers over the time period of our experiments. In a four hour pulse experiment, the immediate TER reduction recovered completely within 48 hours of removal of supernatant. The IEL supernatant evoked fall in TER was not altered by benzamide, an inhibitor of ADP ribosylation which is causally associated with cytokine induced cell death. ${ }^{31}$ We found no change in $\mathrm{LDH}$ concentratons associated with the more dramatic fall in TER which occurred over the longer time period in response to continuous challenge with supernatant. A previous study ${ }^{32}$ has shown that TNF $\alpha$ and IFN $\gamma$ must be released simultaneously by activated mucosal $\mathrm{T}$ cells to kill cells of the human colonic epithelial line HT29. We did not examine reversibility of the changes in TER evoked by 72 hour exposure or of the 
morphological changes. It will be interesting to investigate specific mechanisms by which IEL derived components influence epithelial integrity.

Changes in epithelial cell ultrastructure parallel those associated with human pathology of coeliac disease, which is thought to be a T cell mediated condition. In coeliac disease, the epithelial layer is characterised by early loss of microvilli, subsequent loss of epithelial polarity, and development of nuclear disarray; changes strikingly similar to those found in T84 monolayers after treatment with IEL supernatant. Because the earliest response to wheat protein in coeliac disease is the influx of IELs, it is conceivable based on current data that changes in coeliac small intestine are mediated by factors secreted by IELs.

Simple modelling of the interactions of mucosal cell types represents one approach to studying the immunophysiology of the gut. This reductionist method, in the absence of humoral factors, extrinsic and intrinsic nerves, and the complex native architecture, provides a method with which to examine paracrine regulation of epithelial cell structure and function. We have shown two effects of IEL derived substance(s) on TER across T84 monolayers. The first of these, which was reversible and not associated with gross structural change, may represent alteration of the normally tight epithelium to an immune accessory state ${ }^{19}$ which is relatively permissive to antigen and cellular trafficking between the luminal and lamina propria domains. The later, more severe alteration in epithelial resistance which is coupled with structural damage may represent catastrophic effects normally associated with severe mucosal inflammatory conditions. Although the role of these specialised lymphocytes is still incompletely understood, ${ }^{34}$ our findings may have relevence to a dual role in IEL regulation of epithelial function. Future studies will examine whether IEL derived products regulate permeability of model epithelia to a range of selected macromolecules.

We acknowledge the assistance of Jacqueline Daly and Xue Jun Fan in performing cytokine assays and Cormac O'Connell for the electron micrographs. This work was supported by grants from the Health Research Board and the Wellcome Trust. DK is a Wellcome Senior Fellow in clinical science.

1 Castro GA, Arntzen CJ. Immunophysiology of the gut: a research frontier for integrative studies of the common research frontier for integrative studies of the common
mucosal immune system. Am 7 Physiol 1993; 265: mucosal imm

2 Brandtzaeg P, Halstensen TS, Kett K, Krajci P, Kvale D, Rognum TO, et al. Immunobiology and immunopathology of human gut mucosa: humoral immunity and intraepithelial lymphocytes. Gastroenterology 1989; 97: 1562-84.

3 Cerf-Bensussan N, Beguc B, Gagnon J, Meo T. The human intraepithelial lymphocyte marker HML-1 is an integrin consisting of a beta 7 subunit associated with a distinctive alpha chain. Eur f Immunol 1992; 22: 273-7.

4 Jarry A, Cerf-Bensussan N, Brousse N, Selz F, Guy-Grand D. Subsets of CD3+ (T-cell receptor alpha/beta or gamma delta) and CD3- lymphocytes isolated from normal human gut epithelium display phenotypical features different from their counterparts in peripheral blood. Eur F Immunol 1990; 20: 1097-103.

5 Klein JR, Kagnoff MF. Spontaneous in vitro evolution of lytic specificity of cytotoxic T-lymphocyte clones isolated from murine intestinal epithelia. F Immunol 1987; 138: from 62 .

6 Balk SP, Ebert EC, McDermott FW, Wucherpfennig KW, Landau SB, Blumberg RS. Oligoclonal expansion and
CD1 recognition by human intestinal intraepithelial lymphocytes. Science 1991; 253: 1411-5.
7 Yamamoto M, Fujihashi K, Beagley KW, McGhee JR, Kiyono $\mathrm{H}$. Cytokine synthesis by intestinal intraepithelia ymphocytes. Both gamma/delta $T$ cell receptor positive and alpha/beta $T$ cell receptor positive $T$ cells in the $G 1$ phase of the cell cycle produce IFN-gamma and IL-5. Immunol 1993; 150: 106-14.

8 Holmgren J, Fryklund J, Larsson H. Gamma-interferonmediated down-regulation of electrolyte secretion by intestinal epithelial cells: a local immune mechanism intestinal epithelial cells: a local

9 Madara JL, Stafford J. Interferon gamma directly affects barrier function of cultured intestinal epithelial monolayers. f Clin Invest 1989; 83: 724-7.

10 Kaoutzani P, Colgan SP, Cepek KL, Grant Burkard P, Carlson S, Delp-Archer C, et al. Reconstitution of cultured intestinal epithelial monolayers with a mucosalderived T-lymphocyte cell line. F Clin Invest 1994; 94 788-96.

11 Dharmsathaphorn $\mathrm{K}, \mathrm{McR}$ oberts JA, Mandel KG, Tisdale LG, Masui H. A human colonic tumor cell line that maintains vectorial electrolyte transport. Am $\mathcal{F}$ Physiol 1984; 246: G204-8.

12 Kelleher D, Murphy A, Lynch S, O'Farrelly C. Adhesion molecules utilised in binding of intraepithelia lymphocytes to human enterocytes. Eur $\mathrm{f}$ Immunol 1994; 24: 1013-6.

13 Fan XJ, Chua A, Shahi CN, McDevitt J, Keeling PW, Kelleher D. Gastric T-lymphocyte responses to Helicobacter pylori in patients with $\mathrm{H}$ pylori colonisation. Gut 1994; 35: 1379-84.

14 Mahmud N, O'Connell MA, Stinson J, Goggins MG, Weir $\mathrm{DG}$, Kelleher $\mathrm{D}$. Tumor necrosis factor-alpha and microalbuminuria in patients with inflammatory bowel disease. Eur 7 Gastroenterol Hepatol 1995; 7: 215-9.

15 Barrett KE. Positive and negative regulation of chloride secretion in T84 cells. Am F Physiol 1993; 265: C859-68.

16 Artursson P, Karlsson J, Ockllind G, Schipper N. Studying transport processes in absorptive epithelia. In: Shaw AJ, ed. Epithelial cell culture: a practical approach. New York: Oxford University Press, 1996: 111-34.

17 Sartor RB. Cytokines in intestinal inflammation: pathophysiological and clinical considerations. Gastroenterology 1994; 106: 533-9.

18 Colgan SP, Parkos CA, Delp C, Arnaout MA, Madara JL Neutrophil migration across cultured intestinal epithelial monolayers is modulated by epithelial exposure to IFN- $\gamma$ in a highly polarised manner. F Cell Biol 1993; 120 785-98.

19 Colgan SP, Parkos CA, Matthews JB, D'Andrea L, Awtrey $\mathrm{CS}$, Lichtman $\mathrm{AH}$, et al. Interferon-gamma induces a cell surface phenotype switch on T84 intestinal epithelial surface phenotype switch on 7 P Physiol 1994; 267: C402-10.

20 McRoberts JA, Riley NE. Regulation of T84 colonic epithelial permeability by insulin-like growth factors. $\mathrm{Am}$ f Physiol 1994; 267: C53-43.

21 Adams RB, Planchon SM, Roche JK. Interferon $\gamma$ modulation of epithelial barrier function: time course, reversibility and site of cytokine binding. F Immunol 1993 150: $2356-63$.

22 Reenstra WW. Inhibition of cAMP and Ca-dependent Cl secretion by phorbol esters: inhibition of basolateral $\mathrm{K}$ channels. Am f Physiol 1992; 264: C161-8.

23 Hecht G, Robinson B, Koutsouris A. Reversible disassembly of an intestinal epithelial monolayer by prolonged exposure to phorbol ester. Am 7 Physiol 1994; 266: G214-21.

24 Ojakian GK. Tumor promoter-induced changes in the permeability of epithelial cell tight junctions. Cell 1981 23: 95-101

25 Yanagihara NE,Tachikawa F, Izumi S, Yasugawa $S$ Yamamoto H, Miyamoto E. Staurosporine: an effective inhibitor for $\mathrm{Ca} 2+/$ calmodulin-dependent protein kinase II. $\mathcal{F}$ Neurochem 1991; 56: 294-8.

26 Schindler C K, Shuai K, Prezioso VR, Darnell JE Interferondependent tyrosine phosphorylation of a latent cytoplasmic transcription factor. Science 1992; 257: 809-13.

27 Fukuzawa H, Li PM, Yamamoto C, Murakami Y, Mizuno S, Uehara Y. Specific inhibition of cytoplasmic protein tyrosine kinases by herbimycin A in vitro. Biochem Pharmacol 1991; 42: 1661-7.

28 O'Dell TJ, Kandel ER, Grant SG. Long term potentiation in the hippocampus is blocked by tyrosine kinase in the hippocampus is blocked

29 Graber M, June CH, Samelson LE, Weiss A. The protein tyrosine kinase inhibitor herbimycin A, but not genistein tyrosine kinase inhibitor herbimycin A, but not genistein, specifically inhibits signal transduction by the

$30 \mathrm{McKay}$ DM, Croituru K. Brattsand R, Perdue MH. TNF- $\alpha$ causes epithelial (T84) permeability and secretory abnormalities in a co-culture model of inflammation. Gastroenterology 1994; 106: A732

31 Agarwal S, Piesco NP. Poly-ADP-ribosylation of a $90 \mathrm{kD}$ protein is involved in TNF- $\alpha$ mediated cytotoxicity. $\mathscr{f}$ Immunol 1994; 153: 473-8.

32 Deem RL, Shanahan F, Targan SR. Triggered human mucosal $\mathrm{T}$-cells release tumor necrosis factor- $\alpha$ and interferon- $\gamma$ which kill human colonic epithelial cells. Clin Exp Immunol 1991; 83: 79-84

33 Mahon TM, O'Neill LAJ. Studies into the effect of the tyrosine kinase inhibitor herbimycin A on NF-kappa B activation in T-lymphocytes. Evidence for covalent modification of the p50 subunit. F Biol Chem 1995; 270: 28557-64.

34 Klein JR. Advances in intestinal T-cell development and function. Immunol Today 1995; 16: 322-4 